\title{
A Study of the Character of Lexical Cohesion in ESL Texts
}

\author{
Grace Malgwi \\ American University of Nigeria, Yola, Nigeria
}

\begin{abstract}
This paper discusses the findings of a study that investigated the manifestation of lexical cohesion in written texts of English as Second Language (ESL) pre-service teachers. The data consists of 348 essays written in response to two prompts at a single point in time. Lexical cohesion was identified as the dominant cohesion type in the data. The study also revealed that lexical repetition was the main subcategory of reiteration found to be employed. It is argued that the extensive presence of lexical repetition and the absence of collocation are indicative of level of sophistication of an ESL text. The paper discusses pedagogic implications.
\end{abstract}

\section{Introduction}

Writing even in a first language (L1) is a complex process. The writer engages in a cognitive process of composing a message, draws upon his linguistic resources to represent that message using the graphic symbols of the language while making sure the end product conveys the intended message to the reader. Cameron and Besser [1] define writing as a process in which thoughts and ideas are turned into written language in form of paragraphs, sentences, phrases and words and organized in such a way as to make the content accessible to the intended reader and also fit conventionalized format and text type. For the second language (L2) learner, writing is a demanding activity in view of the limited linguistic resources he possesses in the L2. Kroll [5] asserts that it is the need to understand this complex linguistic activity that has led to the upsurge in scholarship in the area of L2 writing. This upsurge in research in L2 writing is also an acknowledgement of the difficulty faced by L2 writers in expressing themselves accurately and appropriately in the L2. In situations where the L2 is the language of instruction and examination, like the Nigerian context, interest in ESL writing assumes an even greater importance because in such contexts, L2 writing has the potential to determine academic progress of the students where those who are able to manipulate the written language effectively are the ones most likely to succeed in learning and future careers.
L2 writing research has developed to the point where implicit and explicit distinctions are made between first language (L1) and second language(L2) composing strategies and products [3]. Silva [9:696] observed that "L2 writing is strategically, rhetorically and linguistically different in important ways from L1 writing. This means that the analysis of ESL writing can identify textual features that are unique to the ESL writer. This is not to suggest however that ESL writers constitute a homogenous group.ESL writing development involves not just the ability to produce texts with accurate target like structures and complex syntactic constructions but it also entails the ability to produce texts that hang together as unified whole and fulfill the rhetorical conventions related to its communicative purpose. This is described by Reynolds [8:21] as 'the acquisition of linguistic options, a meta-linguistic understanding of those options and the awareness of when to use them. One of these options is the deployment of cohesive devices.

With English as the medium of instruction at every level of education in Nigeria above the lower primary, the importance of writing to the overall academic achievement of the Nigerian student cannot be overemphasized. Students need to express themselves cogently in writing in order to succeed in other school subjects. Students tend to fail not just English but their other school subjects because of their in ability to express their ideas coherently. Furthermore, teachers are apt to use students' writing to gauge students' progress in the language learning process, to identify areas that need further work and also to predict the strengths of the students. Although one can argue the validity of using writing as a general gauge of L2 development, the importance of the writing skill to the ESL learner especially in a classroom learning situation cannot be overstressed.

Taiwo [10] examined the lexico-semantic relations error in ESL writing. The study attempted to determine how cohesion in ESL students' writing is achieved through lexical choices. The findings revealed that the ESL writers had problems defining the Semantic boundaries that separate lexical items thereby making lexical choices that violate the rules of co-occurrence of lexical items. This in turn 
affects the lexical cohesion of the ESL texts. This paper investigates the sub-categories of lexical cohesion predominantly employed in ESL texts.

\section{Lexical Cohesion in English}

The concept of cohesion is a popular one in linguistics. This, however, does not mean there is a general consensus as to its definition. Halliday and Hasan [4] explain cohesion as a semantic concept which refers to the set of possibilities that exist in the language for making texts hang together, which is the relations of meaning that exist within a text that define it as text through the linking of something with what has gone before. Cohesion helps to create texture through meaning relation that requires one element to be interpreted by reference to another. In other words, there is cohesion, where the interpretation of an item in the discourse depends upon reference being made to some other item in the discourse [4:11].

Another linguistic concept closely related to that of Cohesion is Coherence. Cohesion and coherence are related concepts central to text linguistics. McDonough [6:44] explains the concepts as two distinct ways of discussing the features of a text. The first he suggests pertains to the "relations which are present and signalled in the text itself" while the second pertains "those (relations) whose significance is derived from facts outside language". From the foregoing discussion, it can be said that coherence is established by the general, overall, macro, internal and external aspect of the discourse while cohesion is that aspect of coherence evidenced as explicit, surface element sign posts realised by syntactic and lexical elements that guide through the discourse maze by providing sentential linkages.

Lexical cohesion, as explained by Halliday and Hasan [4], refers to the cohesive effect achieved by the selection of vocabulary. There are two categories - Reiteration and Collocation. Reiteration involves the repetition of a lexical item by use of a general word e.g. essay - thing; synonymy e.g. ascent climb; super ordinant e.g. - jaguar, car; or same word e.g. boy-boy. They) emphasized that it is not necessary for two lexical occurrences to have the same referent in order to be cohesive. They give the following as possible referential relationship between two lexical occurrences.

The boy is climbing that tree.

(a)The boy's going to fall if he doesn't care (Identical)

(b)Those boys are always getting into mischief. (Inclusive)

(c)And there is another boy standing underneath (Exclusive)

(d)Most boys love climbing trees (Unrelated). (p 290)
Collocation on the other hand, refers to the lexical cohesion that is achieved through the association of lexical items that co-occur. It is a cohesion between any pair of lexical items that stand to each other in a lexico - semantic, relationship of oppositeness also referred to complementarity, e.g. boy - girl; like - hate; crowded - deserted; it also includes words drawn from the same ordered series e.g. Tuesday - Thursday; dollar - cent; or lexical sets such as red - green; road - rail; car brake; box - lid, chair - table; joke - laugh. The presence of such pairs of words in adjacent sentences generates a cohesive force even though their meaning relation is not easy to identify in systematic semantic terms. Lexical items of this kind can build a long cohesive chain within the same sentence and across sentence boundaries. Commenting on the importance of lexical cohesion to creation of texture, Halliday and Hasan [4] state as follows:

However, luxuriant the grammatical cohesion displayed by a piece of discourse, it will not form a text unless this is matched by cohesive patterning of a lexical kind. (p. 292)

\section{The Study}

The goal of the study was to identify the subcategories of lexical cohesion predominantly employed by the study sample. The purpose was to gain an insight into how ESL writers use vocabulary to enhance textual cohesion.

The data analyzed consists of 348 essays written by 174 pre-service ESL teachers in response to two essay prompts - a narrative and an exposition. A framework of analysis following Halliday and Hasan [4] was adopted. Only aspects of the framework related to lexical cohesion were employed in the analysis of the ESL texts.

Sentences in the texts were numbered serially. An analysis presentation procedure similar to Nwogu [7] was adopted for the study. Thus following Nwogu, any lexical element which functions to hang two sentences together is considered a tie. Each sentence is examined for lexical element which is perceived to link it with the preceding sentence. This process is repeated for every sentence in the text. The lexical items identified were categorized into Halliday and Hasan's [4] sub-categories of lexical cohesion.

\section{Discussion of Findings}

The analysis reveals that the texts cohere mainly by means of lexical cohesion ties. The characteristic lexical means by which the sentences hang together is the repetition of a word or phrase from the preceding sentence using the same wordings. Instances of the use of lexical cohesion are shown below: 
(a) In the city the younger Audu spent his own money carelessly. He did not use his money to start up a business .... Then at a time the money finished.

(b) Secondly, government has deals with the development of agriculture .... Thirdly government has deals with .... Fourthly government has to deal... (c) Prices of foodstuff have risen greatly in Nigeria because government was not helping the people in Nigeria that is why the foodstuff has risen .... In short the government will not taking care of the people that is why the foodstuff is raised.

The characteristic lexical cohesion sub-category in the data is lexical repetition as in (a) where the lexical item "money" is repeated severally in the text. In (b) and (c) similar usage is observed. The lexical item "government" is repeated in three consecutive sentences in (b) while in (c) the repeated lexical items are "foodstuff" "government", "people" "risen". The repetition of these lexical items by virtue of their association with other items in the preceding text, contribute to the textual cohesion of the texts.

Another characteristic feature of the lexical repetition observed in the texts is the tendency to repeat whole phrases or expressions in subsequent sentences using exactly the same wordings. In (b) for instance, the lexical item "government" is repeated along with other lexical items - "has to deals" - in all three sentences. Similarly in (c) the lexical item "foodstuff" is repeated along with the lexical items - "have" risen", is risen". This kind of repetition of several lexical items from a previous sentence occurs characteristically where there is no relation of reference between the occurrences so the repetition functions to compensate, as it were, this lack of referential connection. In examples (b) and (c) however, there exist a same referent relationship between the occurrences of "government" and "foodstuff" and so no compensation function is being performed by the repetition of the lexical items. This kind of reiteration in the study data may be as a result of the developmental nature of the interlanguage. The second category of lexical cohesion, which is collocation, was not found to be characteristic of the study data.

Although lexical cohesion was identified as the dominant cohesion type in the texts, only the simplest and most basic sub-category of reiteration lexical repetition - was found to be employed in the data. A near absence of other lexical reiteration forms such as the use of synonyms, super ordinate words and general words was observed. Lexical repetition is the lowest in the hierarchy of lexical reiteration. Danglli and Abazaji [2:632] argue that there is a close link between the writing process and lexical cohesion/word choice. They further suggest that the use of synonyms contribute, not only to cohesion, but to making a text more "colorful". It can therefore be argued that absence of synonyms and the high occurrence of same word repetition in a text can make the piece of writing dull. It can also be suggested that the predominant presence of lexical repetition and the near absence of collocation is indicative of the level of sophistication of the ESL writers.

\section{Implications for Teaching}

From the findings above, the following pedagogical recommendations are put forward: 1 . More vocabulary development activities should be incorporated into the Nigerian ESL class from the primary to the tertiary levels. The low level use of synonyms, super ordinates words and general words observed suggests a limited vocabulary repertoire. 2 . Reading for writing activities also need to be increased. Reading activities in the ESL class should go beyond just comprehension to include discussion on the lexical connections of the words within the text. This will expose learners to the rich variety of reiteration forms that characterize texts with a high level of sophistication. 3. There is also s need for ESL classrooms to emphasize discourse level features of texts. Learners should be guided to appreciate issues of cohesion and coherence - the elements within the writing that make it a text.

\section{Conclusion}

The study identified the characteristic deployment of lexical cohesion in written texts of pre-service ESL teachers. Halliday and Hasan's [4] framework of cohesion was adopted in analyzing the data. A procedure similar to Nwogu [7] was used in presenting the results. It was observed that sentences in the data hang together mainly by means of lexical ties. It was found that lexical repetition was the predominant sub-category of lexical cohesion employed. It was further observed that the sample tend to repeat whole phrases or expressions in subsequent sentences using exactly the same wordings.

This showed lexical cohesion as the predominant cohesion type in the data with lexical repetition as the characteristic lexical cohesion sub-category employed in the data. Consequently, the use of other forms of lexical reiteration forms such as synonyms, super ordinate words, and general words was minimal.

From the findings, the following conclusions are drawn: First, exact same word repetition suggest a limited repertoire of vocabulary items from which to make varied selection to convey similar meaning. The implication is that ESL teaching within the Nigerian context needs to devote more attention to vocabulary and word relations within the context of 
essay writing. Second, the low occurrence of synonyms, super ordinate words and general words within the study data may be indicative to the level of sophistication of the ESL writers.

\section{References}

[1] Cameron, L. and S. Besser, "Writing in English as an Additional Language at Key Stage 2, Research Report No 586 University of Leeds, 2004.

[2] Danglli, L. and G. Abazaji, "Lexical Cohesion, Word Choice and Synonymy in Academic Writing", Mediterranean Journal of Social Sciences 5/14, 2014 pp. 628-632.

[3] Ferris, D. and J. Hedgcock, Teaching ESL Composition: Purpose, Process and Practice. Erlbaum, Mahwah, NJ, 2004.

[4] Halliday, M.A.K, and R. Hasan, Cohesion in English, Longman, London, 1976.

[5] Kroll, B. Second Language Writing Research: Insights for the Classroom, Cambridge, Cambridge University Press, 1991.

[6] McDonough, S. Applied Linguistics in Language Education, London, Arnold Press, 2002.

[7] Nwogu, K.N., Discourse Variation in Medical Texts: Schema, Theme and Cohesion in Professional and Journalistic Accounts, PhD Thesis, University of Aston in Birmingham, 1989.

[8] Reynolds, D.W., "Linguistic Correlates of Second Language Literacy Development: Evidence from Middlegrade Learner Essays", Journal of Second Language Writing 14, 2005, pp. 19-45.

[9] Silva, T., "Towards an Understanding of the Distinct Nature of L2 Writing: The ESL Research and its Implications", TESOL Quarterly 27, 1993, pp.657-677.

[10] Taiwo, R., "Lexico-Semantic Relations Errors in Senior secondary School Students' Writing", Nordic Journal of African studies,10/3, 2001, pp.306-373. 